\title{
Major Role for Active Extension in the Formation of Processes by ras-Transformed Fibroblasts
}

\author{
Eric Shelden* \\ Department of Anatomy and Cell Biology, University of Michigan, Ann Arbor
}

\begin{abstract}
Expression of constitutively active Ras protein in fibroblasts results in enhanced cell motility, invasion competence and morphological changes including the formation of elongate cellular processes. These processes have been shown to resemble retraction tails formed passively behind nontransformed cells by movement relative to sites of cell-substrate attachment. However, analysis presented here reveals that active extension mechanisms also play a role in the formation of these processes. Extension of distal process ends occurs at $0.42 \pm$ $0.44 \mu \mathrm{m} / \mathrm{min}$ in $\mathrm{ras}$-transformed fibroblasts and accounts for $63.6 \pm 27.5 \%$ of observed process lengths. Active process extension by ras-transformed fibroblasts also persists in the presence of cell-cell contacts. Studies conducted using actin or microtubule antagonists, and correlation of process behavior followed by fixation and immunostaining reveal that process extension requires intact actin and microtubule networks. Other analyses reveal that active extension plays a significantly smaller role in the formation of processes by non-transformed control fibroblasts. These observations demonstrate that constitutively active Ras enhances process extension in fibroblasts and is a causal factor in process extension by fibroblasts in the presence of cell-cell contacts. Moreover, these studies demonstrate that process extension by ras-transformed fibroblasts is accomplished through mechanisms similar to those thought to drive active extension of processes by other cell types including neurons. These findings suggest that extension of cellular processes could play an important role in the metastatic behavior of ras-transformed fibroblasts as well as the response of untransformed fibroblasts to receptor mediated signal transduction events. Cell Motil. Cytoskeleton 42:12-26, 1999. ( 1999 Wiley-Liss, Inc.
\end{abstract}

Key words: microtubule; actin; cytoskeleton; signal transduction; cell motility

\section{INTRODUCTION}

Activation of the small $\mathrm{G}$ protein Ras forms an early step in the cellular response to receptor mediated signaling by hormones and growth factors [Hall, 1993; Hunter, 1997]. Ras function alters both the activity of transcription factors through the function of the MAP kinase signal cascade [Seth et al., 1992] and the actin cytoskeletal system by altering the activation states of the related small G proteins Rac and Rho [Hall, 1992; Prendergast and Gibbs, 1993]. In neurons, activation of Ras in response to nerve growth factor (NGF) or transformation with genes coding for a constitutively active Ras mutant (ras) results in coordinated changes in the regulation of both the actin and microtubule cytoskeletons and the extension of elongate, motile processes or neurites [Bar Sagi and Feramisco, 1985; Thomas et al., 1992; Wood et al., 1992]. Lamellar protrusion driven by actin assembly is thought to provide the motile force required for nerve

Contract grant sponsor: University of Michigan Cancer Research Center; Contract grant sponsor: Rackham Graduate School.

*Correspondence to: Eric Shelden, Department of Anatomy and Cell Biology, University of Michigan, Ann Arbor, MI 48109-0616.

E-mail: shelden@umich.edu

Received 24 February 1998; accepted 25 September 1998 
growth-cone advance and may provide the mechanism for initial neurite protrusion [Cypher and Letourneau, 1992; Heidemann et al., 1990], while a variety of experiments have demonstrated that synthesis of tubulin and microtubule associated proteins and the subsequent formation of stable microtubule bundles are required for maintained neurite outgrowth [reviewed by GordonWeeks, 1991].

Alteration of the cytoskeleton in response to activated Ras has also been documented in fibroblasts. Transformation of fibroblast with ras leads to increases in actin polymerization, membrane ruffling and lamellar protrusion [Ridley et al., 1992], and a reduction in stress-fiber formation [Nobes and Hall, 1995; Ridley and Hall, 1992]. These changes are thought to both increase cell motility and reduce cell-substrate adhesion, and may contribute to the metastasis of cells expressing constitutively active or oncogenic Ras mutants [Lemoine, 1990]. Other studies have documented the formation of elongate cellular processes by ras-transformed fibroblasts, and shown that such processes contain microtubules displaying post-translational modifications common to stable microtubule subpopulations [Prescott et al., 1989]. Processes persist in high-density cultures of ras-transformed but not untransformed fibroblasts. Previous investigators have suggested that these processes could arise by mechanisms analogous to those leading to the formation of retraction "tails" behind nontransformed cells as a consequence of rapid cell movement relative to sites of cell-substrate attachment. Because the formation of trailing retraction tails occurs as a consequence of cell motility driven by motile forces generated at the opposite or leading edge of the cell, this mechanism will be referred to here as "passive elongation." The functional significance, if any, of retraction tails generated by motile fibroblasts is unknown.

The present study was undertaken to directly examine events leading to the formation of cellular processes by ras-transformed fibroblasts. Results presented here reveal that processes generated by ras-transformed fibroblasts display behavior which cannot be accounted for by their formation exclusively through mechanisms thought to generate retraction tails. Specifically, quantitative analysis of process formation from time-lapse video sequences reveals that the distal tips of processes undergo active translocation away from the cell body and initial sites of protrusion. Because this behavior occurs as a consequence of motile activity by processes, it will be referred to here as "active extension." Immunofluorescence analysis of cytoskeletal architecture reveals that processes undergoing active extensions contain cytoskeletal arrays typical of the leading edge of motile cell types and processes extended by neurons. Moreover, process extension by ras-transformed fibroblasts, like that of neuronal cells, is readily inhibited by agents causing the disruption of actin filaments and microtubules. Comparison of process extension in control and ras-transformed fibroblasts further suggests that Ras activation results in an increased rate of extension and length of processes in this cell type and can induce the persistence of process extension behavior in the presence of cell-cell contact. Together, these results demonstrate that active process extension plays an important role in determining the morphology of ras-transformed fibroblasts and suggest that process extension could play a significant role in the metastatic behavior of ras-transformed fibroblasts or the response of untransformed fibroblasts to receptormediated signaling events involving Ras activation.

\section{MATERIALS AND METHODS Cell Culture and Image Acquisition}

NIH3T3 fibroblasts (ATCC) and NIH3T3s transformed with a constitutively active Harvey-ras oncogene (gift of Dr. C. Kent, University of Michigan, see [Ratnam and Kent, 1995]) were cultured at $37^{\circ} \mathrm{C}$ with $5 \% \mathrm{CO}_{2}$ in DMEM containing 10\% donor calf serum (Gibco BRL). Cytochalasin D and nocodazole were purchased from Sigma (St. Louis, MO). To examine cell morphology, cells were harvested by trypsinization, plated into $35 \mathrm{~mm}$ tissue culture dishes and allowed to attach overnight before imaging. For time-lapse analysis of process formation, cells were harvested by incubation in calciummagnesium free PBS for several minutes followed by trituration with culture medium, then seeded at $5 \times 10^{3}$ cells/dish into $35 \mathrm{~mm}$ tissue culture dishes. For analysis of process extension at early times after plating, dishes were equilibrated for $1 \mathrm{~h}$ at $5 \% \mathrm{CO}_{2}$, then sealed with parafilm and placed on a heated microscope stage. For analysis of process extension behavior in established cell cultures, dishes of cells were incubated for 24 to $48 \mathrm{~h}$ before observation. The temperature of culture chambers was maintained at $37^{\circ} \mathrm{C}$ during imaging using an Airtherm Airstream incubator (WPI). Imaging was accomplished on a Zeiss Axiovert equipped with a $10 \times 0.25 \mathrm{NA}$ phase contrast objective lens and a 0.55 NA long working distance condenser. Images were obtained using a monochrome CCD camera (Panasonic WV-BP310) mounted on the microscope's trinocular viewing port using a $0.5 \times$ extension tube. Images were captured at intervals using a Scion LG3 image capture board (Scion Corp., Frederick, MD) installed in an Apple Macintosh computer (PowerPC 7500) using an eight frame integrated average under the control of a macro series of commands written for the NIH-Image program. (NIH Image is a public domain image processing program written by Wayne Rasband at the U.S. National Institutes of Health and available from the Internet by anonymous FTP from 
zippy.nimh.nih.gov or on floppy disk from the National Technical Information Service, Springfield, Virginia, part number PB93-504868.)

\section{Visualization of Microtubule and Actin Filament Networks}

Cells cultured as described above were harvested by trypsinization, plated onto $22 \mathrm{~mm}$ square coverslips in 35 $\mathrm{mm}$ culture dishes and allowed to attach overnight. To visualize actin filament networks alone, cells were fixed for 20 min in PBS containing 4\% paraformaldehyde, then lysed 1 min in PBS containing 0.1\% Triton X-100. Cells were incubated in humid chambers in PBS containing $0.1 \%$ Tween $20,0.02 \%$ sodium azide (PBS-Tw-Az) and $0.2 \mu \mathrm{g} / \mathrm{ml}$ rhodamine phalloidin (Sigma) for $30 \mathrm{~min}$. To visualize microtubule and actin arrays, cells were lysed for $20 \mathrm{~s}$ at room temperature in a microtubule stabilizing detergent buffer $(80 \mathrm{mM}$ Pipes, $5 \mathrm{mM}$ EGTA, $1 \mathrm{mM}$ MgSO4 and 0.5\% Triton X-100 pH 6.8 [Cassimeris et al., 1986]) then fixed for $20 \mathrm{~min}$ in $2 \%$ paraformaldehyde and $0.1 \%$ gluteraldehyde in PBS pH 7.3. Gluteraldehyde autofluorescence was quenched by incubation for $1 \mathrm{~h}$ in PBS containing 1\% sodium borohydrate. Fixed cells were incubated in PBS-Tw-Az containing a 1:200 dilution of primary antibodies made up in $1 \mathrm{mg} / \mathrm{ml} \mathrm{BSA}$ for $1 \mathrm{~h}$ at room temperature, washed three times for $5 \mathrm{~min}$ in PBS-Tw-Az, and incubated for $1 \mathrm{~h}$ in PBS-Tw-Az/BSA containing a 1:200 dilution of secondary antibodies. For double-labeling of microtubules and actin, fluorescent phalloidin was added to secondary antibody solutions at a final concentration of $0.2 \mu \mathrm{g} / \mathrm{ml}$. For double-labeling of tyrosinated and acetylated tubulin, cells were first incubated with antiacetylated tubulin primary and secondary antibodies, followed by incubation with antityrosine tubulin primary and secondary antibodies. Antiacetylated tubulin antibodies (clone 6-11B-1) and all secondary antibodies were purchased from Sigma. The YL-1/2 anti-tyrosine tubulin antibody [Kilmartin et al., 1982] was purchased from Accurate Chemical and Scientific (Westbury, NY). Cells were mounted in $0.01 \mathrm{mg} / \mathrm{ml} \mathrm{n-}$ phenylene diamine, $10 \% 10 \times$ PBS and $90 \%$ glycerol on microscope slides. Preparations were sealed with nail polish and imaged on a Zeiss Axiovert 135 equipped with an AtoArc $100 \mathrm{~W}$ epifluorescent illuminator and a $100 \times$ 1.3 NA objective lens. Images were collected using NIH-Image to drive an integrating monochrome CCD camera (Dage model RT3000). Images were contrast enhanced using NIH-Image and Adobe Photoshop, and final image montages created and labeled using Adobe Photoshop. Image magnifications were determined by imaging a slide micrometer.

\section{Quantitative Analysis of Process Extension}

Process total length, extended length and rate of extension were quantified using NIH-Image. The initial formation of processes was identified by viewing image sequences in reverse order and determining the time and location of initial protrusion. One end of a line selection marker was fixed at the site of process initiation. The video sequence was then observed in foreword order until active extension was no longer observed. This time point was noted and the length of the process extended away from the fixed site of initial protrusion, as well as the distance from the site of protrusion to the cell body was measured. Total process length was measured from the distal process tip to the point at which the process diameter began to increase near the cell body. In cases where lateral movement of the process occurred during the image sequence, the point of process origin was determined by generating a line perpendicular to the axis of the process and through the initial point of process protrusion. The intersection of this line and the process was used as the process origin. Data obtained using these approaches were analyzed and graphed using Microsoft Excell, and final figures were composited using Claris Draw.

\section{RESULTS \\ Process Morphology in Cultures of Control and Ras-Transformed Fibroblasts}

NIH3T3s are an immortalized line of murine fibroblasts which display contact inhibition of growth and motility [Greig et al., 1985]. When cultured at low densities, individual cells display a varied morphology and can appear flattened and polygonal or adopt a fan-shaped morphology typical of motile fibroblasts (Fig. 1a). Slender cellular processes or retraction tails of varying length are observed behind such motile cells and terminate in a finely tapered point. Other cells may display varying degrees of polarization leading to the generation of thin cellular processes and the establishment of an elongate, spindle-shaped morphology (Fig. 1a) similar to that described by previous authors for fibroblasts of other origins [Tomasek and Hay, 1984]. At higher densities, processes are observed infrequently in control cell population, and these cells are characterized by a flattened polygonal morphology (Fig. 1b).

Transformation of NIH3T3 fibroblasts with the constitutively active Harvey-ras oncogene ( ras) results in unregulated growth and motility, and the generation of an altered cell shape characterized by elongate cellular processes ([Lloyd et al., 1989] Fig. 1c,d). Although many cells displayed only one or two process, cells displaying more processes are common (Fig. 1c). In addition, two distinct process morphologies are observed. In some cases, processes terminate in a gradually tapered point (arrow, Fig. 1c), and closely resemble retraction tails described by previous investigators [Chen, 1981] and observed here for some nontransformed cells (Fig. 1a). In 


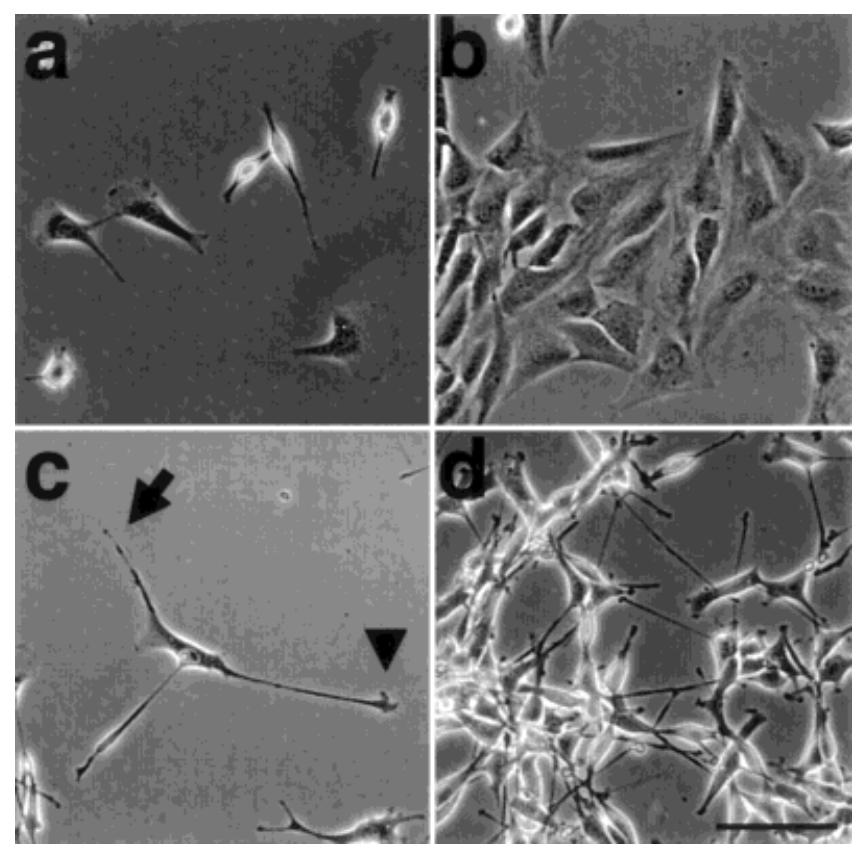

Fig. 1. Morphology of control and ras-transformed NIH3T3 fibroblasts at low and high culture densities. a: Nontransformed NIH3T3s cultured at low density are fan-shaped and display trailing, tapered processes or spindle-shaped morphologies. b: Nontransformed NIH3T3s at higher culture densities form contact-inhibited monolayers and display a polygonal morphology. c: NIH3T3s transformed with a constitutively active Harvey-ras oncogene generate elongate cellular processes when cultured at low densities. These processes may terminate in a tapered point (arrow) or a small, fan-shaped region displaying membrane ruffles (arrowhead). d: Ras-transformed cells generate similar cellular processes at high culture densities. Bar $=$ $100 \mu \mathrm{m}$.

other instances, processes terminate in a fan-shaped region displaying membrane extensions resembling lamellar ruffles or small pseudopods (arrowhead, Fig. 1c). Process formation by ras-transformed fibroblasts used in these studies persists at high culture densities (Fig. 1d), consistent with earlier reports [Prescott et al., 1989].

\section{Active Extension of Processes by Normal and Ras-Transformed Fibroblasts}

To examine the formation of cellular process by ras-transformed fibroblasts, cells were harvested by trituration and examined within $2 \mathrm{~h}$ of replating in tissue culture dishes. Quantitative analysis of time-lapse video images reveals that process extension and cell migration driven by lamellar protrusion are separable events. For example, examination of a typical time course of process formation by ras-transformed fibroblasts reveals that initial processes formation arises in large part as a result of active translocation of the distal process tip away from the site of initial protrusion (arrowhead, Fig. 2a) and relative to the substrate. In the example shown, the maximal length of the indicated process at $94 \mathrm{~min}$ is 60 $\mu \mathrm{m}$. Of this, $31 \mu \mathrm{m}(52 \%)$ of process length can be attributed to movement of the distal process tip away from the initial site of protrusion. Movement of the cell center away from the site of process extension accounts for the remaining length of the process, but begins only $40 \mathrm{~min}$ after process extension (see also Fig. 2b). Examination of these images also reveals that process extension by ras-transformed fibroblasts is not accomplished by the initial formation and subsequent constriction of a large lamella, and may therefore be distinguishable from some types of processes generated by the treatment of cells with pharmacological activators of protein kinase C [Bershadsky et al., 1990; Lyass et al., 1988]. However, small, dynamic protrusions are observed at the distal end of this process throughout extension. Such dynamic protrusions characterized all observed processes while undergoing active extension $(n=48$; data not shown).

Figure $2 \mathrm{~b}$ provides quantitative analysis of process behavior shown in Figure 2a. Examination of these graphs reveals that the initial $40 \mathrm{~min}$ of process formation occurs almost entirely by process extension in the absence of cell movement and leads to translocation of the distal process tip over a distance of $20 \mu \mathrm{m}$. Between 40 and $50 \mathrm{~min}$ of observation, movement of the cell body away from the site of initial protrusion occurs and accounts for an additional rapid increase in process length. However, translocation of the distal process end relative to the substrate continues and is largely unaltered during movement of the cell body, illustrating that process extension can occur despite motion of the cell body in another direction. Together, these qualitative and quantitative data reveal that process extension and cell migration under these conditions are temporally separable events and occur at distinct rates.

When ras-transformed fibroblasts are cultured at high cell densities, they form aggregates of cells called "foci" [reviewed by Clark et al., 1995]. To determine if process extension continues to play a role in the formation of processes by aggregating cells, cells at the margin of forming aggregates were examined $48 \mathrm{~h}$ after plating. Figure $2 \mathrm{c}$ illustrates the formation of a cellular process at the edge of a small group of cells. Although movement of the multicellular mass accounts for some elongation of this process, active extension relative to the site of initial protrusion generates over half of the final observable process length. Extension of the process occurred at an average rate of $0.1 \mu \mathrm{m} / \mathrm{min}$ over a period of $490 \mathrm{~min}$ (final distance was $43 \mu \mathrm{m}$ ) and accounted for $63 \%$ of the observed total process length. Interestingly, this rate is roughly four times slower than the average rate of extension measured for ras-transformed cell immediately after plating. Observation of similar image sequences sug- 


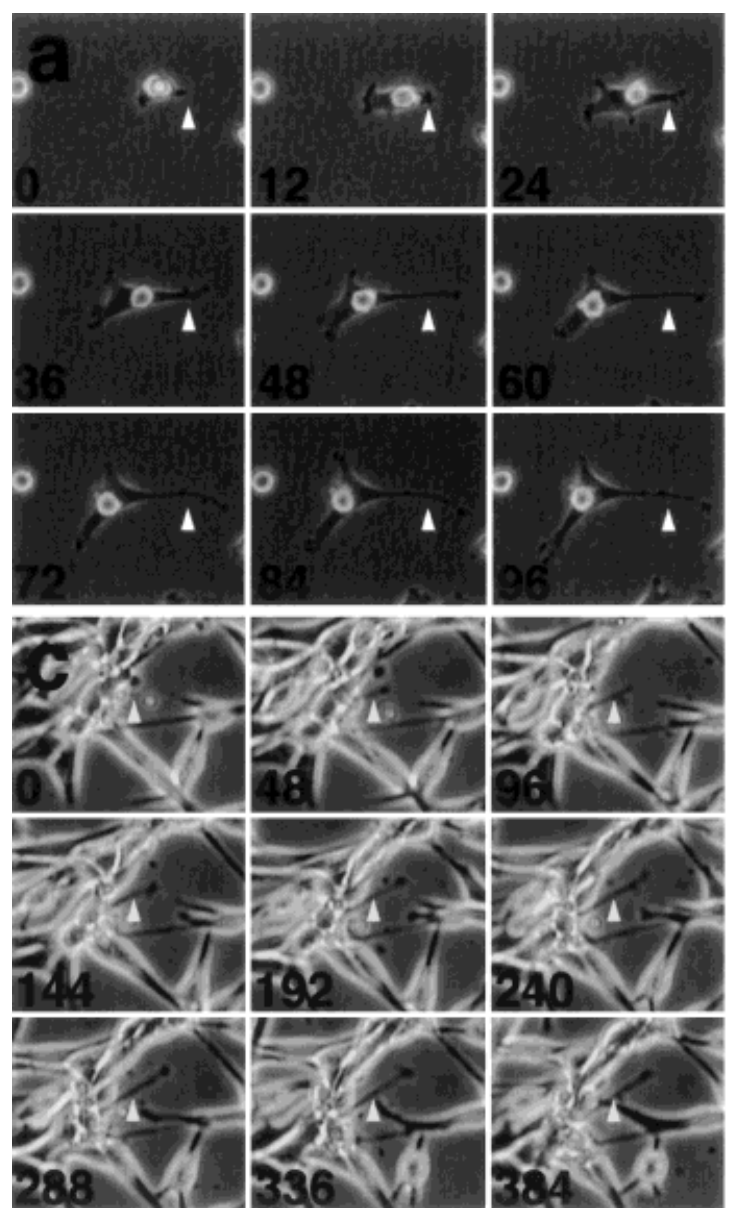

Fig. 2. Time lapse images of cellular process extension by rastransformed fibroblasts. a: Process formation by a ras-transformed NIH3T3 fibroblast originates with the formation of a small protrusion (arrowhead marks the initial site of protrusion in all panels). Subsequent images obtained from an image series acquired at 1 min intervals show that dynamic changes in morphology of the distal process end accompany its movement away from the initial site of protrusion. Movement of the cell away from the site of initial protrusion also contributes to final process length. b: Graphs displaying changes in

gests that slow but persistent process extension may be a general characteristic of extending processes in high density cultures of ras-transformed fibroblasts (not shown).

Nontransformed NIH3T3 fibroblasts do not commonly display processes when contact inhibited (Fig. 1 [Prescott et al., 1989]). To examine the formation of processes by nontransformed fibroblasts, the behavior of well separated NIH3T3s was examined at early times after plating in tissue culture dishes. Figure $2 d$ illustrates a time course of processes extension observed for a typical nontransformed NIH3T3 fibroblast within $2 \mathrm{~h}$ of plating. Like extension observed for ras-transformed fibroblast, the formation of the process observed here arises as a consequence of both active extension and passive elongation. However, only $21 \%$ (17.5 of $83.1 \mu \mathrm{m})$

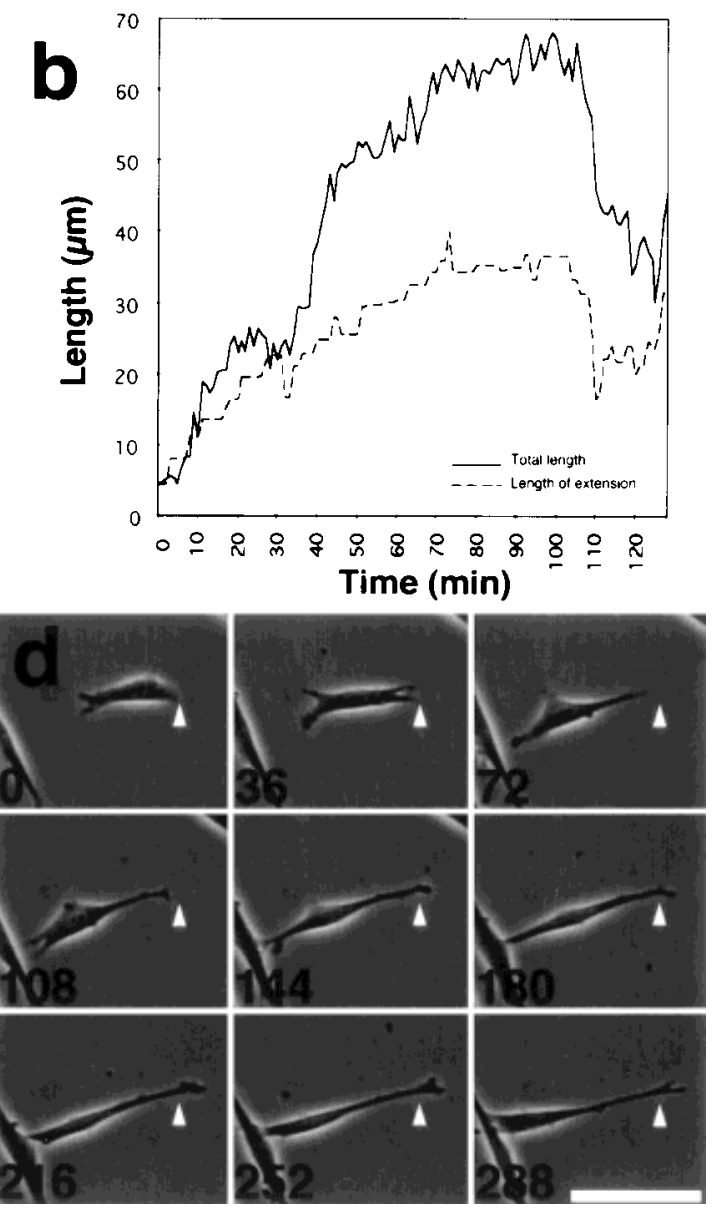

total process length (solid line) and the proportion of length attributable to extension (dashed line) for the process indicated in a. Process extension occurs over $40 \mathrm{~min}$ prior to movement of the cell in a different direction (0-40 min) and continues both during and after movement of the cell in a different direction. c: Process extension continues at the edge of cellular aggregates formed in established cultures of ras-transformed NIH3T3 fibroblasts. d: Process extension is a minor component of process generation by nontransformed NIH3T3 fibroblasts. Numbers indicate minutes. Bar $=50 \mu \mathrm{m}$.

of the length of this process results from active extension over a 78 min period.

\section{Rates and Extent of Process Extension Are Increased in Ras-Transformed Fibroblasts}

Table 1 presents a comparison of process extension behavior measured from time lapse image sequences of control and ras-transformed NIH3T3s obtained at early times after plating. Results were obtained from three independent experiments for each cell type. The average rate and length of process extension were significantly greater in ras-transformed fibroblasts compared to control cells $(P<0.05)$ as was the proportion of process length attributable to active extension $(P<0.1)$. Although these data confirm that transformation with consti- 
TABLE I. H-ras Transformation Significantly Increases Parameters of Process Extension Behavior in NIH3T3 Fibroblasts

\begin{tabular}{lccc}
\hline & $\begin{array}{c}\text { ras-NIH3T3 } \\
(\mathrm{n}=40)\end{array}$ & $\begin{array}{c}\text { NIH3T3 } \\
(\mathrm{n}=22)\end{array}$ & $P$ value \\
\hline Total length $(\mu \mathrm{m})$ & $63.7 \pm 47.9$ & $57.2 \pm 23.8$ & $P<0.5$ \\
\% of length extended & $63.6 \pm 27.5$ & $48.7 \pm 35.0$ & $P<0.1$ \\
Extended length $(\mu \mathrm{m})$ & $38.8 \pm 22.1$ & $26.1 \pm 18.2$ & $P<0.05$ \\
Extension rate $(\mu \mathrm{m} / \mathrm{min})$ & $0.42 \pm 0.44$ & $0.16 \pm 0.14$ & $P<0.05$ \\
\hline
\end{tabular}

$P$ values are calculated using a Student's two-tailed $t$-test.

tutively active Ras enhances the ability of fibroblasts to extend processes, it should be noted that nontransformed cells are also capable of active process extension. Surprisingly, although cultures of ras-transformed cells appeared to contain more processes than those of nontransformed controls (not shown), significant differences in the total length of processes generated by ras-transformed and nontransformed NIH3T3s were not detected. However, because these experiments were conducted over periods of only a few hours, it is possible that slow but persistent extension of processes could result in greater lengths of processes in ras-transformed cells cultures over longer periods of time or that processes generated by rastransformed cells are retracted less frequently than those generated by nontransformed cells. Because a larger proportion of process lengths in nontransformed NIH3T3s is attributable to cell movement relative to the distal end of processes, these data also suggest that nontransformed cells are relatively motile at low cell densities.

\section{Cells Can Migrate in the Direction of Process Extension}

Extending processes were occasionally observed to form the advancing edge of motile cells. For example, the cell illustrated in Figure 3 displays translocation of the distal process tip first toward the top of the field, and then turning toward the upper right hand corner. Movement of the cell body occurs in part by cell contraction, but clearly follows the direction of the motile process tip over times 0 to $60 \mathrm{~min}$. This image series also illustrates transient process extension opposite the direction of cell movements (compare the length and position of the trailing process at 20 and $40 \mathrm{~min}$ ) and that process extension lateral to the direction of movement can occur (arrows). This image sequence also illustrates that the bipolar cell morphology is not a stable configuration for these rastransformed fibroblasts; process extension in directions other than the direction of cell movement result in the formation of a quadrapolar cell at $80 \mathrm{~min}$.

\section{Cytoskeletal Architecture of Processes Formed by Ras-Transformed Fibroblasts}

To identify cytoskeletal elements which might be involved in process extension, the behavior of cellular
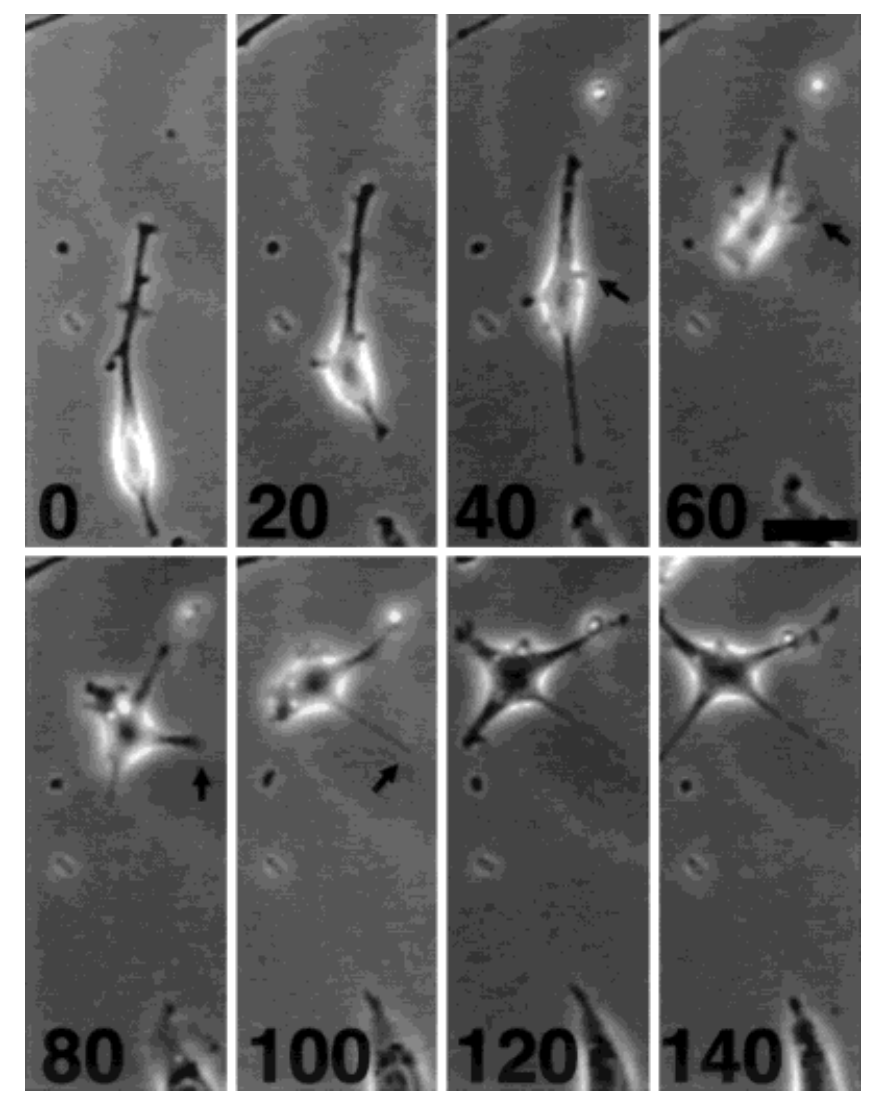

Fig. 3. Extending processes form the leading edge of motile, rastransformed fibroblasts. Movement of the cell occurs partly by retraction of the cell body toward the distal process tip, and partly as a result of translocation of the process tip toward the upper right-hand corner of the field. Rearward (20-40 min) and lateral process extension (arrows) is evident and results in the formation of a multipolar cell. Numbers indicate minutes. Bar $=40 \mu \mathrm{m}$.

processes prior to fixation was correlated with cytoskeletal architecture visualized after fixation using immunostaining techniques. Figure $4 \mathrm{a}$ reveals that distal membrane protrusions accompanying process extension are brightly stained with fluorescent phalloidin, suggesting they contain F-actin meshworks similar to those found at the leading edge of other motile cell types. In contrast, processes which have begun to retract lack distal membrane protrusions (inset, Fig. 4b) and do not display bright distal staining with phalloidin (Fig. 4b). Analysis of time-lapse video sequences reveals that loss of distal membrane protrusions occurred prior to actual process retraction in 20 of 21 observed retraction events (not shown).

Comparison of the distribution and extent of posttranslationally modified microtubules within processes also suggests that the distal ends of extending processes are characterized by dynamic microtubule populations. When extending processes are immunolabeled with antibodies specific for acetylated tubulin, faint staining of linear cytoskeletal elements is apparent within the stalk- 

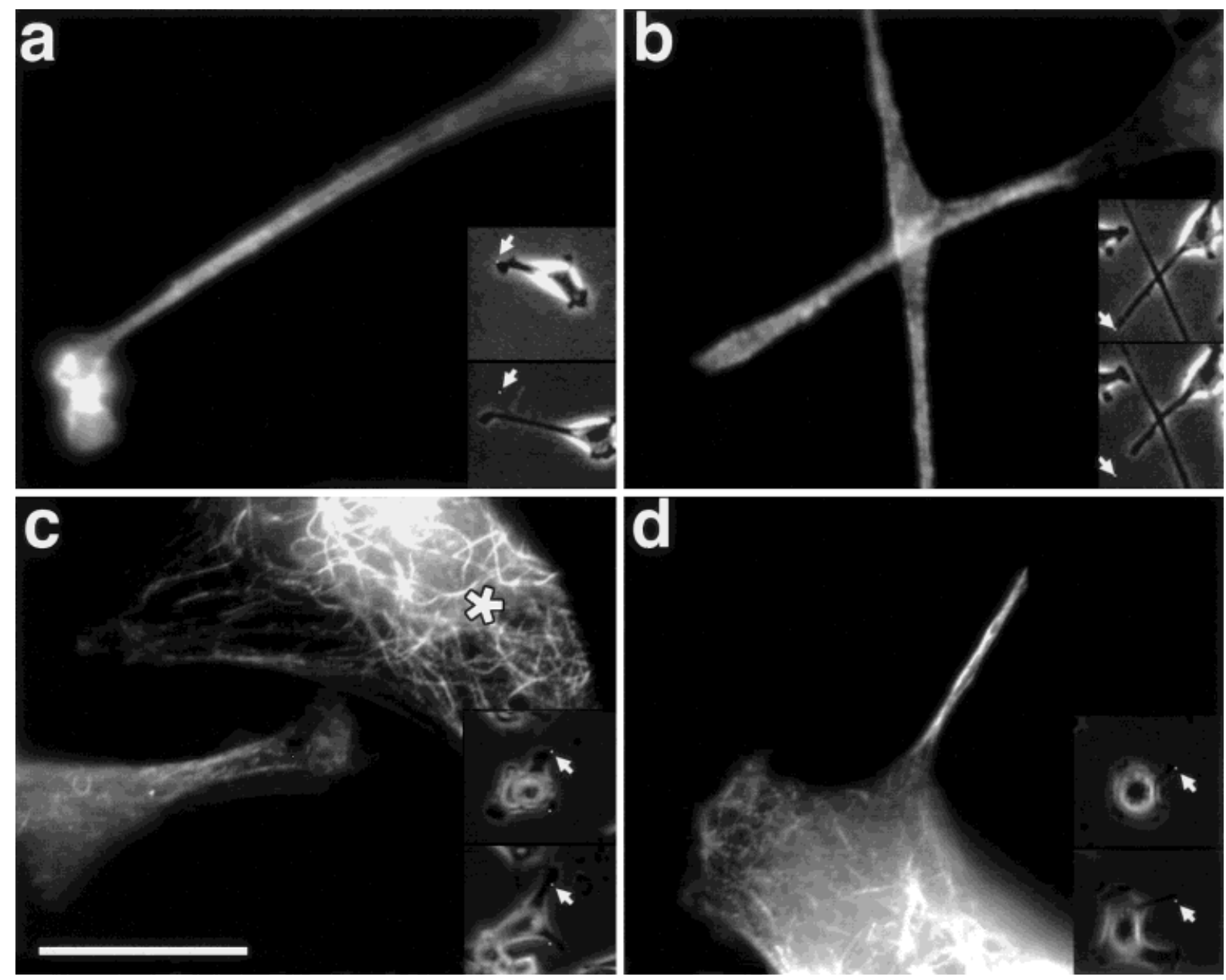

Fig. 4. Processes undergoing extension contain terminal F-actin meshworks but few post-translationally modified microtubules. a: A process undergoing active extension is observed after fixation and staining with fluorescent phalloidin. Bright staining of membrane protrusions is observed at the distal tip. b: A process undergoing retraction lacks distal membrane protrusions and is not brightly stained by fluorescent phalloidin after fixation (arrows). c: A process undergoing extension displays faint staining with antibodies specific for acetylated tubulin. However, the antiacetylated tubulin staining pattern and intensity within this process is neither as uniform nor as bright as microtubules

like portion of extending processes (Fig. 4c). However, microtubules found in the perinuclear region of neighboring cells (asterisk, Fig. 4c) and those found within processes not undergoing active extension (Fig. 4d) are much more brightly stained, and the staining pattern appears to be more evenly distributed along the length of individual microtubules. Highly acetylated microtubules extend to the distal tip of non-moving (Fig. 4d), but not actively extending (Fig. 4c) processes. Because acetylation of tubulin subunits characterizes stable and longlived microtubules [Schulze et al., 1987], these observations suggest that the distal ends of actively extending processes contain microtubules which are newly polymerized and may be less stable than those found in the center

present in the perinuclear region of a neighboring cell (asterisk). d: A process which does not change length over the same interval is stained brightly and uniformly by antiacetylated tubulin antibodies. The small white dots in phase contrast images are fiduciary marks transferred to all images in a sequence and used to determine the initial position of process ends. Insets:Interval between phase contrast images is $70 \mathrm{~min}$ (a), $8 \mathrm{~min}$ (b), and $60 \mathrm{~min}(\mathrm{c}, \mathrm{d})$. Arrows mark the location of the process tip at the start of imaging. Lower images were obtained just before fixation. Bar $=10 \mu \mathrm{m}$ (fluorescence images) and $112 \mu \mathrm{m}$ (phase images).

of cells, the stalk-like portion of established processes, and the distal ends of unmoving processes.

Processes shown in Figure 4 were formed shortly before fixation. To examine the distribution of acetylated and tyrosinated microtubules in longer, more established processes, cells were fixed after overnight culture but without prior video analysis of motility behavior, and the microtubule staining pattern correlated with the morphology or F-actin content of the distal process end. Microtubules stained with antityrosine tubulin antibodies are found within the distal ends of processes displaying F-actin rich membrane protrusions and may be found coincident with their distal margins (arrows, Fig. 5a, $\mathrm{a}^{\prime}$ ). A second example (Fig. 5b, $b^{\prime}$ ) was obtained by focusing 
above the substrate plane on an upwardly directed lamella. Three bright spots of antitubulin staining are observed within this region (arrows) and, as suggested by their similarity to microtubules observed in cross section in our previous study [Shelden and Knecht, 1998], may
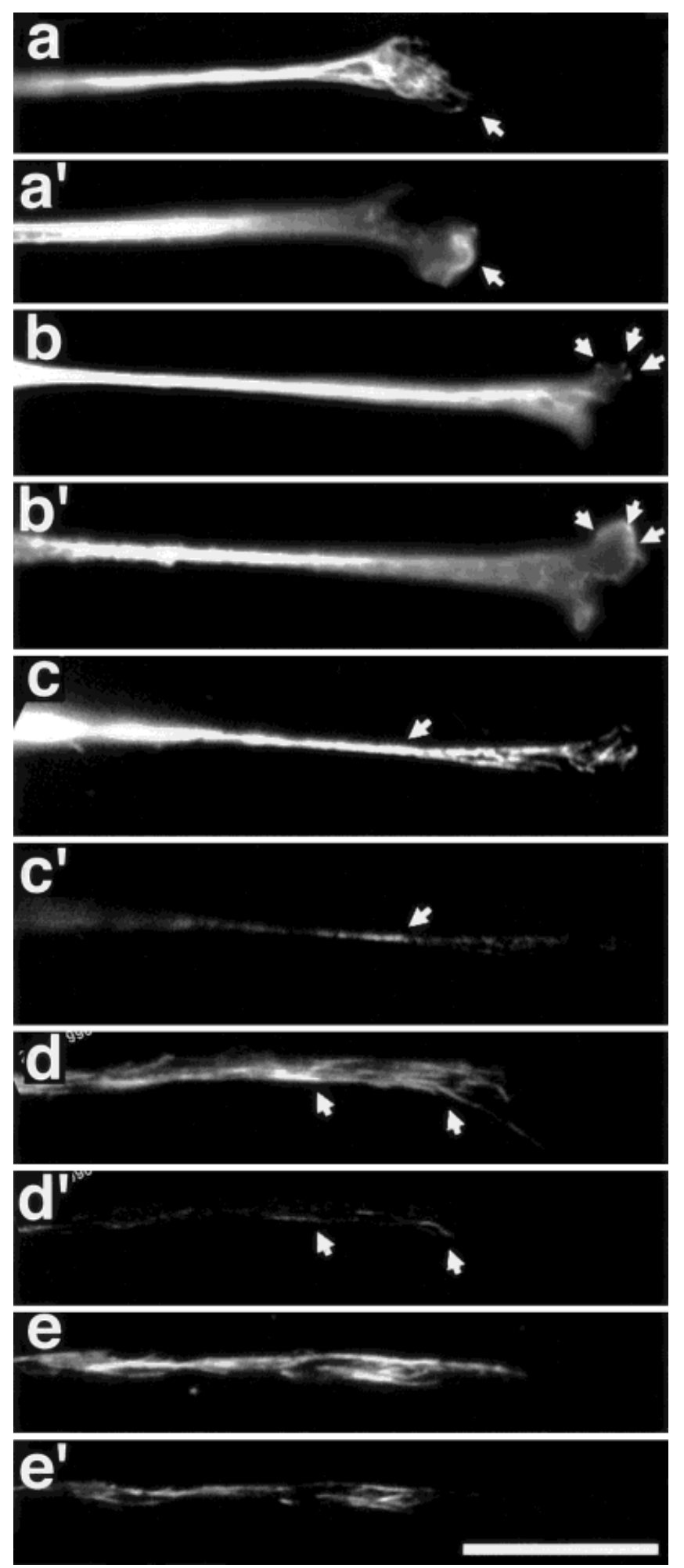

represent microtubules projecting upward. Because tyrosine tubulin characterize newly polymerized microtubules [Shulze et al., 1987], these data suggest that the distal ends of processes are a site of net microtubule polymerization or dynamic turnover.

Double labeling with antibodies specific for acetylated and tyrosinated tubulin further indicates that although microtubule stabilization occurs within processes, the distal ends of extending processes largely contain dynamic microtubules (Fig. 5c-e). Examination of Figure $5 \mathrm{c}$ and Figure $6 \mathrm{~d}$ reveals that only short lengths of microtubules within processes bearing fan-shaped or flared distal ends stain efficiently with antiacetylated tubulin antibodies (Fig. 5c', $\mathrm{d}^{\prime}$ ) while antibodies specific for tyrosine tubulin stain microtubules throughout these same processes (Fig. 5c,d). In contrast, the ends of processes displaying morphology similar to that shown in Figure $4 \mathrm{~b}$ and Figure $4 \mathrm{~d}$ contain a relatively higher proportion of microtubules which are stained with antiacetylated tubulin antibodies (Figure 5e). The morphology of this process suggests that its distal end is not undergoing active extension (see Figure 4b,d). The staining pattern of processes lacking distal fan-shaped protrusions (Figure 5e) resembles that reported by earlier investigators [Prescott et al., 1989] and for other elongate processes lacking distal membrane protrusions observed in the present study.

\section{Microtubule and Actin Inhibitors Prevent Process Extension by Distinct Mechanisms}

To investigate the role of individual cytoskeletal systems in process extension, cells cultured overnight in tissue culture dishes were treated with varying concentrations of the microtubule inhibitor nocodazole or the actin

Fig. 5. Cellular processes contain tyrosinated microtubules but few acetylated microtubules. F-actin $\left(\mathrm{a}^{\prime}, \mathrm{b}^{\prime}\right)$, acetylated tubulin $\left(\mathrm{c}^{\prime}, \mathrm{d}^{\prime}, \mathrm{e}^{\prime}\right)$ and tyrosine tubulin distribution $(\mathrm{a}, \mathrm{b}, \mathrm{c}, \mathrm{d}, \mathrm{e})$ revealed by staining with fluorescent phalloidin, antiacetylated and YL-1/2 primary antibodies and fluorescent secondary antibodies within processes generated by ras-transformed NIH3T3s. a: Processes ending in fan-shaped lamellae contain free ends of microtubules, while microtubules found within the stalk-like portion of these processes are closely approximated. Individual microtubule ends can extend to the distal end of fan-shaped processes at the level of the light microscope $\left(\mathbf{b}^{\prime}\right)$ (arrow marks the same location in both images). b: In a second example, a focal plane off the cell substrate demonstrates that microtubules enter upward membrane protrusions. Bright spots of antitubulin staining are apparent and may represent microtubules projecting upward (arrows). c: Antityrosine tubulin staining of a process displaying a fan-shaped or flared distal end reveals numerous microtubules. Antiacetylated tubulin staining of this process $\left(\mathbf{c}^{\prime}\right)$ reveals only a small area of efficient staining in the stalk-like portion of this process. A similar relative distribution of tyrosine tubulin (d) and acetylated tubulin $\left(\mathbf{d}^{\prime}\right)$ is seen in a second example. In contrast, processes which do not display fan-shaped or flared ends display a relatively higher content of acetylated tubulin $\left(\mathbf{e}^{\prime}\right)$ relative to tyrosine tubulin $(\mathbf{e})$. Bar $=15 \mu \mathrm{m}$. 
inhibitor cytochalasin D. Both total process lengths and the movement of the distal tip of processes (excursion) were measured after drug addition. Population lengths of processes are not altered by treatment with solvent $(0.3 \%$ DMSO) alone (Fig. 6a). In contrast, cells treated with 2 $\mu \mathrm{M}$ nocodazole rapidly retract established cellular processes, although small, dynamic protrusions continue to be generated from the margins of the rounded cell bodies (arrowheads, Fig. 6b). Application of $0.2 \mu \mathrm{M}$ nocodazole failed to induce rapid retraction of processes, and both lamellar ruffling and some extension of existing processes continued at early times post drug addition (Fig. $6 \mathrm{c}$; see also Fig. 8b). However, examination of cell morphology after $2.3 \mathrm{~h}$ of incubation (Fig. 6c) and quantitative analysis of process lengths in these experiments (Fig. 7, below) indicate that $0.2 \mu \mathrm{m}$ nocodoazole is sufficient to induce more gradual retraction of processes (arrows in Fig. 6c mark individual cells at 1 and $2.3 \mathrm{~h}$ of incubation). Application of an actin assembly inhibitor (cytochalasin D) also inhibited the extension of cellular processes by ras-transformed cell. However, some differences in the response of cells to this agents were also observed. Cells treated with $2 \mu \mathrm{M}$ cytochalasin D (Fig. 6d) became highly rounded after drug addition and further shape changes were not observed. Retraction of processes was frequently accompanied by breaking of the processes stalk, leaving the distal process end attached to the substrate (arrowheads, Fig. 6d). Breakage of processes was observed less frequently in nocodazole treated cells (see Fig. 6b). Application of $0.2 \mu \mathrm{M}$ cytochalasin D also induced rapid retraction of a subset of existing cellular processes (arrows, Fig. 6e). However, although growth of existing processes was not observed post drug addition, many processes appeared to be resistant to this concentration of cytochalasin (see also Fig. 7, below). Together, these results demonstrate that both actin and microtubules are essential for the maintenance and elongation of processes, although initial protrusion events may be microtubule independent.

Quantitative analysis of overall process lengths in drug treated cell populations further illustrates the differences in the response of processes to actin and microtubule inhibitors (Fig. 7). Although application of $2 \mu \mathrm{M}$ nocodazole and cytochalasin D cause an immediate retraction of existing processes, the responses of processes to lower concentrations of these drugs are more gradual and occur with distinct kinetics. $0.2 \mu \mathrm{M}$ cytochalasin treated cells rapidly loose about half of the total length of process, but processes remaining after $1 \mathrm{~h}$ of drug treatment are more resistant. In contrast, $0.2 \mu \mathrm{M}$ nocodazole causes more gradual retraction of processes within the population of examined cells, and no resistant subpopulation of processes is detected over the duration of this experiment.
Finally, because the analysis described in Figure 7 reveals only changes in overall process length, the extension and retraction behavior of the distal tip of individual processes were independently analyzed. Results of this analysis (Fig. 8) confirm that active extension of processes is completely inhibited by the application of $2 \mu \mathrm{M}$ concentrations of both cytochalasin D (Fig. 8e) and nocodazole (Fig. 8c) and at $0.2 \mu \mathrm{M}$ concentrations of cytochalasin D (Fig. 8d). In contrast, active extension of the distal ends of cellular processes can continue in the presence of $0.2 \mu \mathrm{M}$ nocodazole (Fig. $8 \mathrm{~b}$ ), although both the proportion of extending processes in the population and the rate of process extension is reduced as compared to control cells treated with DMSO alone (Fig. 8a).

\section{DISCUSSION \\ Processes Generated by Ras-Transformed Fibroblasts Undergo Active Extension}

NIH3T3 fibroblasts have provided an important model system in the study of signal transduction systems and oncogene function [reviewed by Clark et al., 1995]. Transformation of these cells with genes coding for a constitutively active Ras mutant (ras) causes unregulated cell division and motility in vitro and the induction of metastatic potential in vivo [Greig et al., 1985], and is accompanied by changes in cell morphology and cytoskeletal regulation, including the formation of elongate cellular processes [Lloyd et al., 1989; Prescott et al., 1989]. Such processes resemble retraction tails formed by untransformed cells as a consequence of cell movement relative to stationary sites of substrate attachment [Chen, 1981; Dunn, 1980], and have been observed behind motile ras-transformed fibroblasts displaying fan-shaped leading lamellae [Prescott et al., 1989]. However, analysis presented here reveals that processes generated by both ras-transformed NIH3T3 fibroblasts and untrans-

Fig. 6. Processes are retracted by ras-transformed NIH3T3 fibroblasts after application of microtubule (nocodazole) and actin (cytochalasin D) inhibitors. a: Application of DMSO $(3.3 \mu \mathrm{l} / \mathrm{ml})$ does not inhibit process formation or induce process retraction. b: Application of $2 \mu \mathrm{M}$ nocodazole causes rapid retraction of existing processes. Small membrane protrusions continue to be generated in the presence of nocodazole (arrowheads), but do not reestablish processes. c: Application of $0.2 \mu \mathrm{M}$ nocodazole does not result in rapid process extension, but most cells do retract their processes with longer incubation periods (arrows indicate cells at 1 and $2.3 \mathrm{hr}$ ). d: Application of $2 \mu \mathrm{M}$ cytochalasin D causes rapid retraction of existing processes and cell rounding. Process retraction is accompanied by fragmentation of the process, often leaving the distal process end attached to the substrate (arrowheads). Protrusive activity is completely abolished. e: Application of $0.2 \mu \mathrm{M}$ cytochalasin $\mathrm{D}$ causes rapid loss of some processes (arrowheads), but others are resistant. Continued protrusion of process ends is not observed. Numbers are times (hr:min) post drug addition. Bar $=90 \mu \mathrm{m}$. 

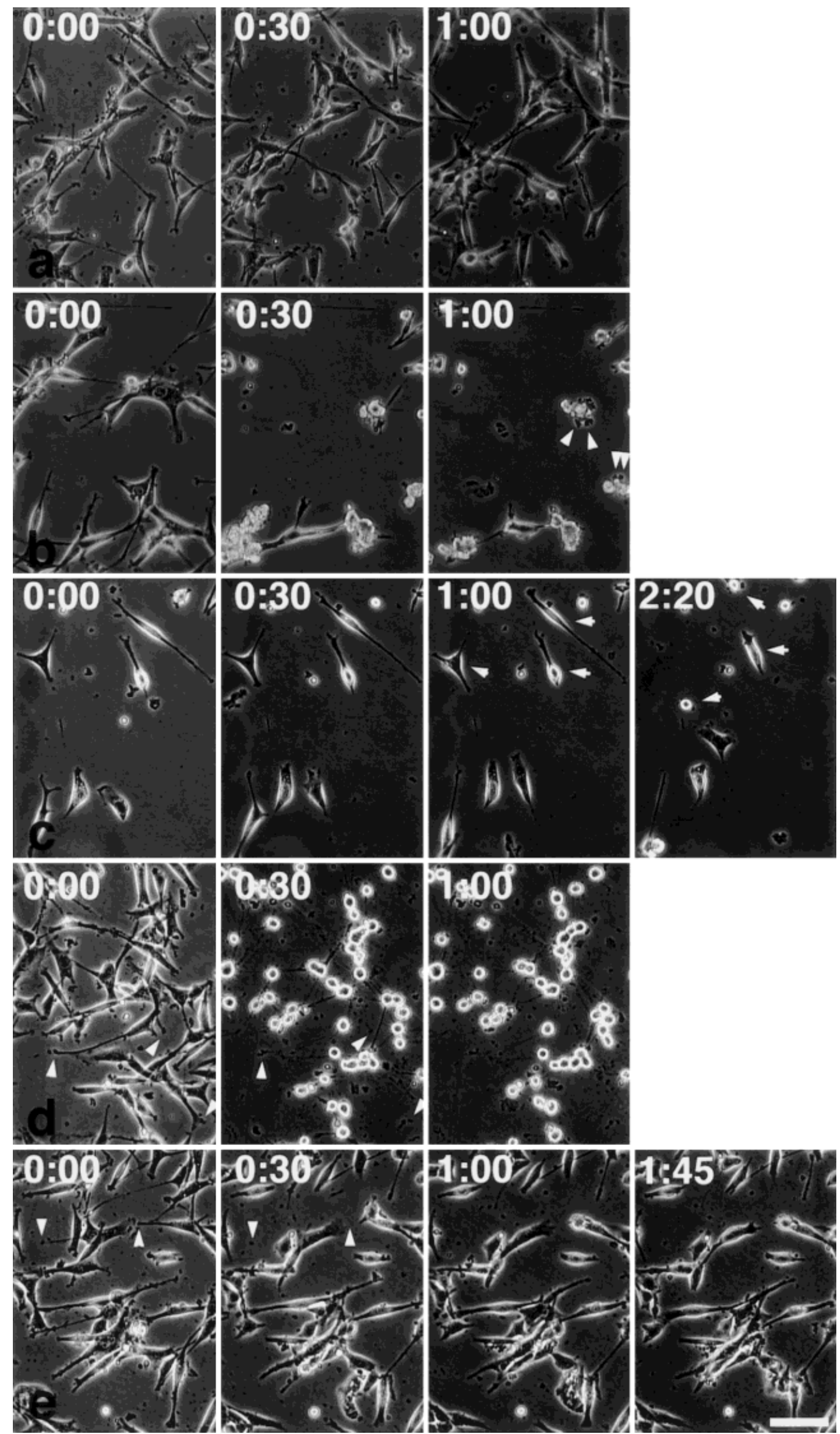

Figure 6 . 
formed controls also undergo active extension mediated by translocation of the distal process tip away from the cell body. Active process extension is not consistent with the formation of these structures by mechanisms thought to cause the formation of retraction tails. Quantitative analysis of active processes extension and the passive elongation of processes as a consequence of cell movement further reveals that these two behaviors occur at distinct rates and may be temporally separable. Although on average processes are generated through the function of both mechanisms, active extension alone generated some processes observed in the present study. Further observations demonstrate that movement of the distal process tip may generate traction forces sufficient to mediate cell movement. Finally, although the majority of cells analyzed in the present study were observed at short times after initial plating, observation of cell behavior after periods of up to 2 days in culture reveals that active process extension continues in ras-transformed but not untransformed fibroblast cultures at high cell densities. Although the precise role of process extension in the motility of normal and ras-transformed fibroblasts remains to be determined, these results demonstrate that active process extension plays a significant role in development of the cell morphology characterizing rastransformed fibroblasts.

\section{Process Extension Mechanisms Are Similar in Different Cell Types}

Cellular processes characterize a variety of cell types including neurons, glomerular podocytes, motile fibroblasts, dendritic cells, and some types of glial cells. Process formation has been most thoroughly studied in neurons, as the extension of cellular processes forms the basis for the extension of neurites. Neurite extension is accomplished by the generation of distal lamellar protrusion at sites known as growth cones. Although growth cone advance in some organisms appears to be microtubule independent [Smith, 1988], studies have shown a close correlation between microtubule assembly within the growth cone and the regulation of growth cone movement in neurons cultured from many organisms [Tanaka and Kirschner, 1995; Tanaka and Sabry, 1995]. Maintenance of growth cone morphology and advance in such neurons is inhibited by low concentrations of microtubule depolymerizing drugs [reviewed by GordonWeeks, 1991], suggesting that active extension of neurites requires microtubule assembly. The extension of cellular processes by ras-transformed fibroblasts described in the present study is strikingly similar to neurite outgrowth in these respects. Advancing cellular processes contain microtubules which bear antigenic similarity to newly polymerized microtubules. Process extension by ras-transformed fibroblasts is inhibited at submicromolar concentrations of nocodazole and abolished at higher nocodazole concentrations. Moreover, reported rates of neurite extension in vitro [Argiro et al., 1984] are in good agreement with that reported here for extension of processes by ras-transformed fibroblasts. Rates of process extension by both neuronal cells and fibroblasts are also significantly slower than the motility of cells in which microtubules are not thought to play a significant role such as Dictyostelium amoebae $(8 \mu \mathrm{m} / \mathrm{min})$ [Shelden and Knecht, 1995; Wessels et al., 1988] and specialized epidermal cells such as fish keratocytes (up to $25 \mu \mathrm{m} / \mathrm{min}$ ) [Small et al., 1996]. It is of some interest to consider whether slow, microtubule-dependent movement mediated by process extension could play a general role in the migration of cells within tissues and extracellular matrices, while less restrained migration of cells over surfaces might occur through more rapid, microtubule independent mechanisms.

Microtubules displaying post-translational modifications are also a major component of axonal processes, but are not found within growth cones during neurites outgrowth and accumulate gradually during axon regeneration [Hadley and Miller, 1995; Lim et al., 1989]. Similarly, studies presented here also reveal that posttranslationally modified microtubules are not a major component of the distal ends of rapidly extending processes, but are observed in more proximal regions of extending processes and within non-moving processes. These findings, and the detection of a population of processes resistant to low levels of cytochalasin, suggest that post-translationally modified microtubules may play a role in process stabilization after initial extension. Additionally, Prescott et al. [1989] have previously demonstrated that processes at the edges of cellular aggregates or foci of ras-transformed fibroblasts contain abundant microtubules comprised of acetylated tubulin. In the present study, processes extension observed at the margin of cellular aggregates occured at slower rates than the extension of processes observed at early times after plating. Thus, it is possible that microtubule stabilization plays a direct role in the extension of processes by ras-transformed fibroblasts in the presence of cell-cell contact.

Although processes generated by ras-transformed fibroblasts and neuronal cells share obvious similarities, some differences in process extension by these two cell types should also be noted. For example, the formation of stable microtubules within neuronal processes requires the synthesis and microtubule bundling activity of the microtubule associated proteins MAP2 and tau [Drubin et al., 1985]. However, morphological changes in NIH3T3s can be induced by the introduction of oncogenic Ras in the presence of protein synthesis inhibitors [Lloyd et al., 1989]. Although process extension was not directly 


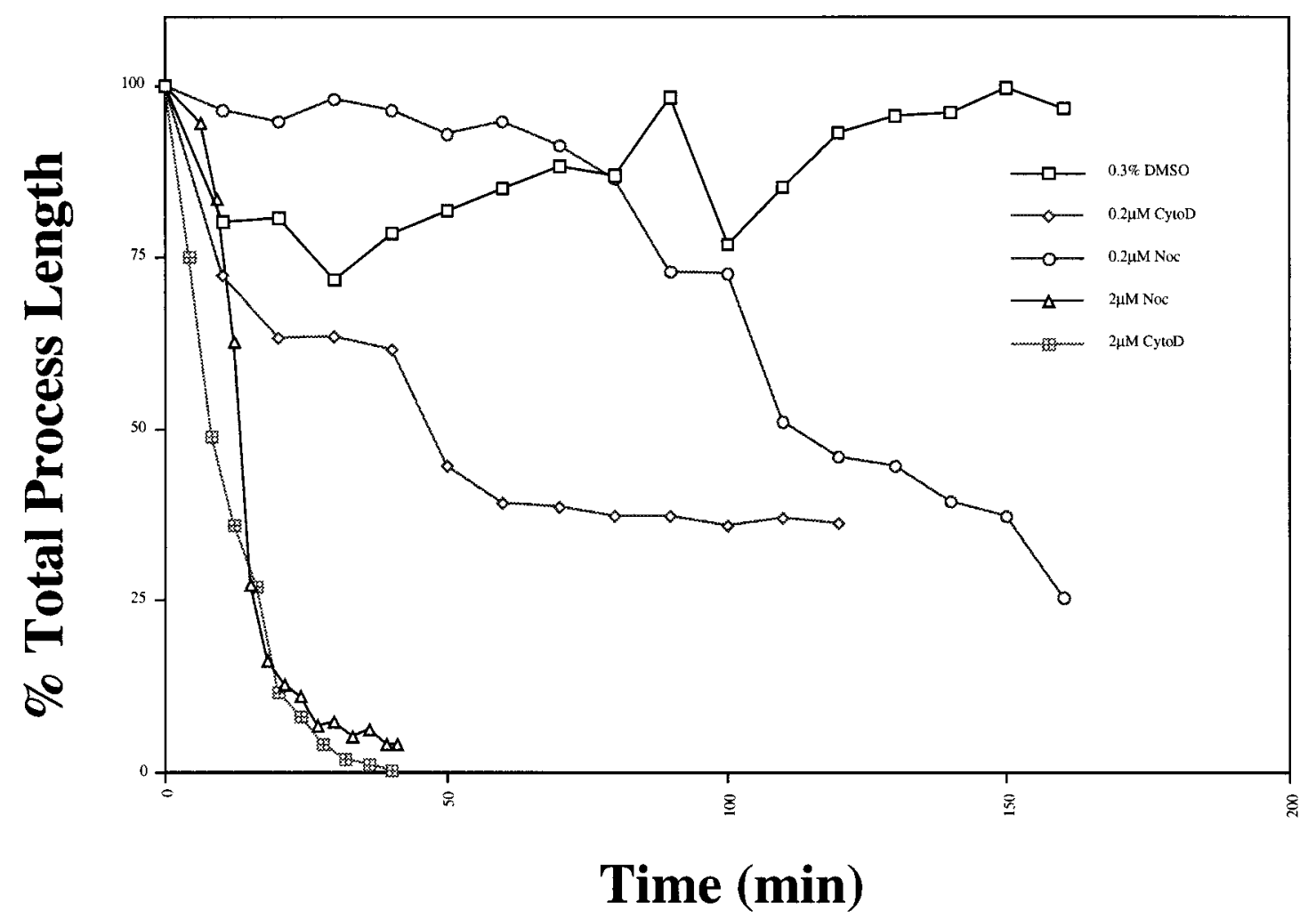

Fig. 7. Microtubule and actin inhibitiors inhibit processes by distinct mechanisms. DMSO $(n=15)$ alone causes no overall change in the length of processes within treated cell populations. Graphs of process length measured for cells treated with $2 \mu \mathrm{M}$ cytochalasin $\mathrm{D}(\mathrm{n}=15)$ and nocodazole $(\mathrm{n}=12)$ show rapid and complete loss of processes. Cytochalasin at $0.2 \mu \mathrm{M}(\mathrm{n}=14)$ causes rapid initial retraction, but some processes are more resistant. Nocodazole at $0.2 \mu \mathrm{M}(\mathrm{n}=23)$ causes more gradual retraction of processes, but a resistant subpopulation is not detected.

examined in this previous study, it is therefore likely that the formation of cellular processes by ras-transformed cells does not require increased expression levels of tubulin or microtubule-associated proteins. Similarly, although recent studies have shown that proteins with antigenic similarity to neuronal tau are expressed by fibroblasts [Ingelson et al., 1996; Matsuyama and Bondareff, 1994], these proteins are expressed in fibroblasts only at low levels and their function in this cell type has not been determined. Higher expression levels of the microtubule-associated protein MAP4 are expressed in fibroblast [Bulinksi and Borisy, 1980], and MAP4 could therefore play a role in stabilizing microtubules within processes observed in the present study. However, although loss of MAP4 expression has been shown to inhibit the polarization of myotubes during differentiation [Mangan and Olmsted, 1996], experimental reduction of MAP4 levels in fibroblasts has not been shown to alter microtubule distribution or stability [Wang et al., 1996]. Thus, unlike processes generated by neuronal cells, the extent to which microtubule bundling by MAPs plays a role in the generation of processes by transformed fibroblasts remains unclear.

\section{The Role of Ras in Process Extension by Fibroblasts}

Nontransformed control fibroblasts observed in this study were observed to extend processes when cultured at low cell densities, and thus it remains possible that the activation of Ras is not required for process extension. However, cells in this study were cultured in the presence of serum growth factors and receptor activation by a number of growth factors is expected to activate endogenous Ras in nontransformed fibroblasts observed here. Additionally, the results of the present study reveal that the presence of constitutively active Ras significantly enhances the rates of process extension by fibroblasts, and results in the persistence of process extension behavior at high cell density. These findings suggest that the activation of Ras could play a direct role in process extension by fibroblasts. Additional recent studies have shown that process-like cellular extensions are generated 

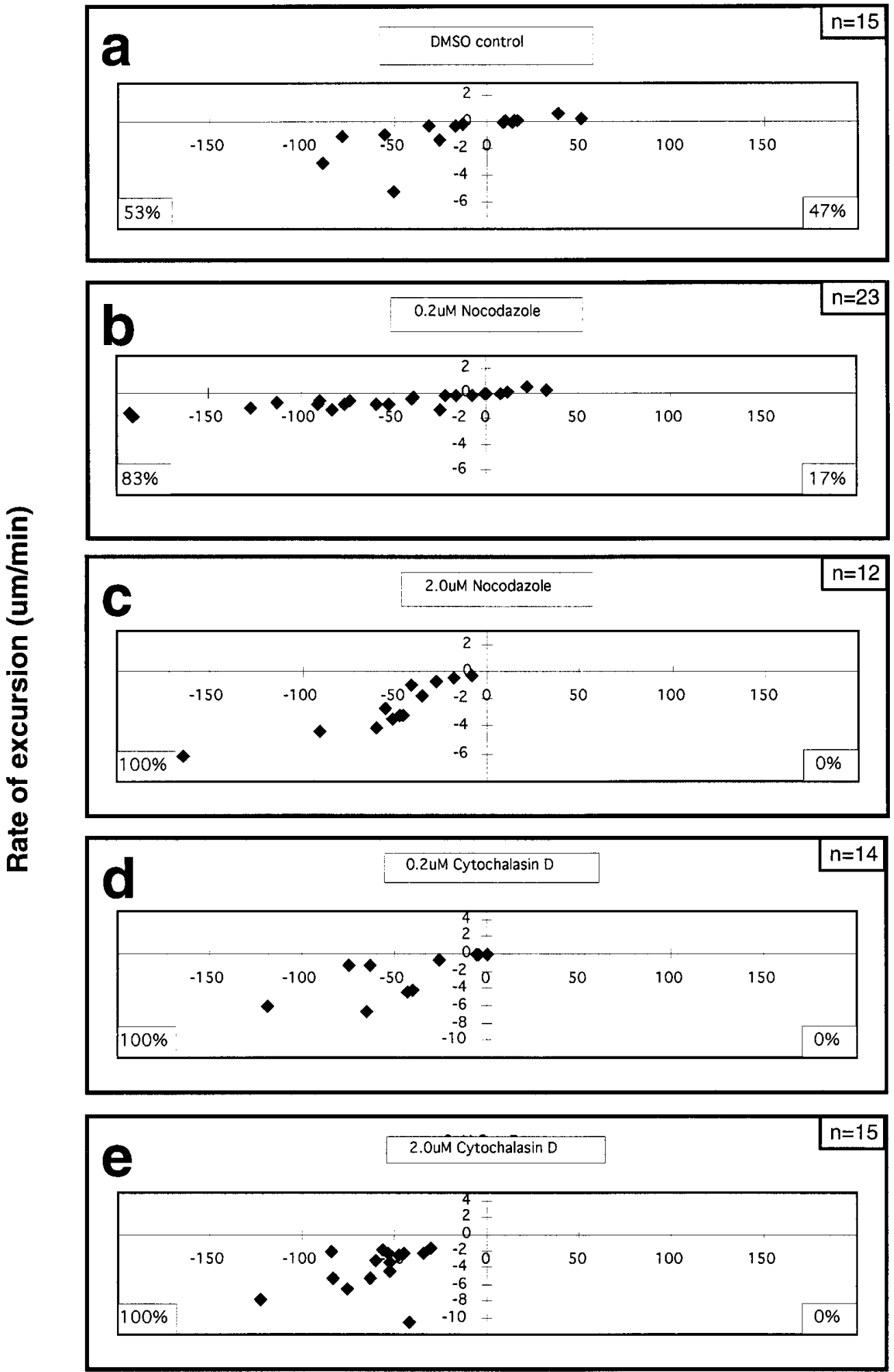

\section{Excursion length (um)}

Fig. 8. Active process extension is inhibited by microtubule (nocodazole) and actin (cytochalasin D) inhibitors. Process extension and retraction were measured with reference to the position of the distal process tip at the time of inhibitor application. Numbers in the corners of each panel are the proportion of observed retracting processes (bottom left) extending processes (bottom right) and total number of processes analyzed (top right). a: Processes observed after the application of DMSO $(10 \mu \mathrm{l} / 3 \mathrm{ml})$ undergo both extension and retraction in approximately equal proportion. b: Nocodazole at $0.2 \mu \mathrm{M}$ does not completely prevent extension, but both the length and proportion of extension events are reduced as compared to DMSO controls. c: Nocodazole at $2 \mu \mathrm{M}$ completely inhibits process extension. d: Cytochalasin $\mathrm{D}$ at $0.2 \mu \mathrm{M}$ is sufficient to completely prevent extension. e: Cytochalasin D at $2 \mu \mathrm{M}$ induces additionally increased rates of retraction. 
by fibroblasts treated with the Rho inhibitor Botulinum C3 exoenzyme and an inhibitor of the Rho effector p160ROCK [Hirose et al., 1998]. However, results of similar studies have also suggested that Rho protein function is essential for the generation of morphological changes induced by oncogenic Ras [Khosravi-Far et al., 1995]. Because neither the rates nor microtubuledependence of process extension was directly addressed in these previous studies, the function of Rho in the generation of processes described in the present study remains to be established. However, these previous studies do provide initial evidence suggesting that the downstream Ras effector Rho plays a direct role in the extension of cellular processes by fibroblasts under some conditions.

\section{Functional Significance of Process Extension in Fibroblast}

Finally, the observation that processes generated by ras-transformed fibroblasts undergo extension invites evaluation of their functional significance. Nontransformed fibroblasts display processes at low, but not high culture densities, suggesting that process extension is inhibited by cell-cell contact in untransformed fibroblasts, while process formation by ras-transformed fibroblasts is density independent. The average rate of process extension measured here are consistent with values reported for neurite outgrowth, suggesting that process extension could provide the basis of cell movement through tissues at physiologically relevant rates. Moreover, previous studies have shown that cell body movement of ras-transformed fibroblasts can become directed toward a former process [Prescott et al., 1989], and observations presented here demonstrate that translocation of the distal ends of processes may mediate cell migration. Together, these studies suggest that process formation could play a role in the initial transit of barriers to normal cell migration, and allow subsequent invasive movement of the cell body. The possibility that process extension is an element of invasion is supported by other lines of evidence, including the documentation of invasive cellular processes formed by cultured tumor cells in an in vitro assay of invasion [Mueller et al., 1992].

Alternatively, ras-transformed cells may display behavior appropriate to the response of nontransformed cells to extracellular signaling events such as the receptor binding of developmental and chemotactic factors. Although the migration of fibroblasts in vitro is often characterized by the extension of leading, fan-shaped lamellae, previous investigators have noted that fibroblasts cultured in three-dimensional collagen matrices adopt a bipolar spindle-like morphology characterized by opposing cellular extensions [Tomasek and Hay, 1984].
Results of the present study provide further evidence that process extension may directly mediate cell motility. Thus, it is possible that normal movement of the fibroblasts in vivo during development or the deposition of oriented collagen fibers during wound healing and tissue maintenance requires the establishment of polarized cell shape resulting from process extension.

\section{ACKNOWLEDGMENTS}

This work was supported in part by grants to E. Shelden from the University of Michigan Cancer Research Center and the University of Michigan's Rackham Graduate School. I thank Drs. Susan Brown and Rainer Benndorf (University of Michigan, Dept. of Anatomy and Cell Biology) for critical reading of this manuscript and Ms. Kathleen Farrel for expert technical assistance.

\section{REFERENCES}

Argiro V, Bunge MB, Johnson MI. 1984. Correlation between growth form and movement abd their dependence on neuronal age. $\mathrm{J}$ Neurosci 4:3051-3062.

Bar Sagi D, Feramisco JR. 1985. Microinjection of the ras oncogene protein into PC12 cells induces morphological differentiation. Cell 42:841-846.

Bershadsky AD, Ivanova OY, Lyass LA, Pletyushkina OY, Vasiliev JM, Gelfand IM. 1990. Cytoskeletal reorganizations responsible for the phorbol ester-induced formation of cytoplasmic processes: Possible involvement of intermediate filaments. Proc Natl Acad Sci USA 87:1884-1888.

Bulinksi JC, Borisy GG. 1980. Widespread distribution of a 210,000 mol wt microtubule-associated protein in cells and tissues of primates. J Cell Biol 87:802-808.

Cassimeris LU, Wadsworth P, Salmon ED. 1986. Dynamics of microtubule depolymerization in monocytes. J Cell Biol 102: 2023-2032.

Chen W-T. 1981. Mechanism of retraction of the trailing edge during fibroblast movement. J Cell Biol 90:187-200.

Clark GJ, Cox AD, Graham SM, Der CJ. 1995. Biological assays for Ras transformation. Methods Enzymol 255:395-412.

Cypher C, Letourneau P. 1992. Growth cone motility. Curr Opin Cell Biol 4:4-7.

Drubin DG, Feinstein SC, Shooter EM, Kirschner MW. 1985. Nervegrowth factor-induced neurite outgrowth in PC12 cells involves the coordinate induction of microtubule assembly and assemblypromoting factors. J Cell Biol 101:1799.

Dunn GA. 1980. Mechanisms of fibroblast locomotion. In: Durtis ASG, Pitts JD, editors. Cell adhesion and motility. Cambridge: Cambridge University Press, p 409-423.

Gordon-Weeks PR. 1991. Growth cones: the mechanism of neurite advance. Bioessays 13:235-239.

Greig RG, Koestler TP, Trainer DL, Corwin SP, Miles L, Kline T, Sweet R, Yokoyama S, Post G. 1985. Tumorigenic and metastatic properties of "normal" and ras-transfected NIH/3T3 cells. Proc Natl Acad Sci USA 82:3698-3701.

Hadley RD, Miller JD. 1995. The regulation of acetylated microtubules during outgrowth from cultured neurons of the snail, Helisoma. Dev Brain Res 89:129-138.

Hall A. 1992. Ras-related GTPases and the cytoskeleton. Mol Biol Cell 3:475-479. 
Hall A. 1993. Ras-related proteins. Curr Opinion Cell Biol 5:265-268. Heidemann SR, Lamoureux P, Buxbaum RE. 1990. Growth cone behavior and production of traction force. J Cell Biol 111:19491957.

Hirose $\mathrm{M}$, Ishizaki $\mathrm{T}$, Watanabe $\mathrm{N}$, Uehata $\mathrm{M}$, Kranenberg $\mathrm{O}$, Moolenaar WH, Matsumura F, Maekawa M, Bito H, Narumiya S. 1998. Molecular dissection of the rho-associated protein kinase (p160ROCK)-regulated neurite remodeling in neuroblastoma N1E-115 cells. J Cell Biol 141:1625-1636.

Hunter T. 1997. Oncoprotein networks. Cell 88:333-346.

Ingelson M, Vanmechelen E, Lannfelt L. 1996. Microtubule-associated protein tau in human fibroblasts with the Sewdish Alzheimer mutation. Neurosci Lett 220:9-12.

Khosravi-Far R, Solski PA, Clark GJ, Kinch MS, Der CJ. 1995. Activation of Rac1, RhoA, and mitogen-activated protein kinases is required for Ras transformation. Mol Cell Biol 15:6443-6453.

Kilmartin JV, Wright B, Milstein C. 1982. Rat monoclonal antitubulin antibodies derived from a new nonsecreting cell line. J Cell Biol 93:576-582.

Lemoine N. 1990. Ras oncogenes in human cancer. In: Sluyser M, editor. Molecular biology of human cancer genes. England: Ellis Horwood, West Sussex.

Lim S-S, Sammak PJ, Borisy GG. 1989. Progressive and spatially differentiated stability of microtubules in developing neuronal cells. J Cell Biol 109:253-263.

Lloyd AC, Patterson HF, Morris JD, Hall A, Marshall CJ. 1989. p21H-ras induced morphological transformation and increase in c-myc expression are independent of functional protein kinase C. Embo J 8:1099-1104.

Lyass LA, Bershadsky AD, Vasiliev JM, Gelfand IM. 1988. Microtubule-dependent effect of phorbol ester on the contractility of cytoskeleton of cultured fibroblasts. Proc Natl Acad Sci USA 85:9538-9541.

Mangan ME, Olmsted JB. 1996. A muscle-specific variant of microtubule-associated protein 4 (MAP4) is required in myogenesis. $\mathrm{J}$ Cell Sci 122:771-781.

Matsuyama SS, Bondareff W. 1994. Tau-like immunoreactivity in Alzheimers and control skin fibroblasts. J Neurosci Res 39:519524.

Mueller SC, Yeh Y, Chen WT. 1992. Tyrosine-phosphorylation of membrane proteins mediates cell invasion by transformed cells. J Cell Biol 119:1309-1325.

Nobes CD, Hall A. 1995. Rho, Rac and Cdc42 GTPases regulate the assembly of multimolecular focal complexes associated with actin stress fibers, lamellipodia and filopodia. Cell 81:53-62.

Prendergast GC, Gibbs JB. 1993. Pathways of ras function: connections to the cytoskeleton. Adv Cancer Res 62:19-64.

Prescott AR, Vestberg M, Warn, RM. 1989. Microtubules rich in modified alpha-tubulin characterise the tail processes of motile fibroblasts. J Cell Sci 94:227-236.

Ratnam S, Kent C. 1995. Early increase in Choline-kinase activity upon induction of the H-ras oncogene in mouse fibroblast cell lines. Arch Biochem Biophys 323:313-322.

Ridley AJ, Hall A. 1992. The small GTP-binding protein rho regulates the assembly of focal adhesions and actin stress fibers in response to growth factors. Cell 70:389-399.

Ridley AJ, Paterson HF, Johnston CL, Diekmann D, Hall A. 1992. The small GTP-binding protein rac regulates growth factor-induced membrane ruffling. Cell 70:401-410.

Seth A, Gonzalez FA, Gupta S, Raden DL, Davis RJ. 1992. Signal transduction within the nucleus by mitogen-activated protein kinase. J Biol Chem 267:24796-24804.

Shelden E, Knecht DA. 1998. Reconstruction and display of curvilinear objects from optical section data using 3-D curve fitting algorithms. J Microsc 109:97-107.

Shelden E, Knecht DA. 1995. Mutants lacking myosin II cannot resist forces generated during multicellular morphogenesis. J Cell Sci 108:1105-1115.

Shulze E, Asai DJ, Bulinski JC, Kirschner M. 1987. Posttranslational modification and microtubule stability. J Cell Biol 105:21672177.

Small JV, Anderson K, Rottner K. 1996. Actin and the coordination of protrusion, attachment and retraction in cell crawling. Biosci Rep 16:351-368.

Smith SJ. 1988. Neuronal Cytomechanics: The actin-based motility of growth cones. Science 242:708-714.

Tanaka E, Kirschner MW. 1995. The role of microtubule in growthcone turning at substrate boundaries. J Cell Biol 128:127-137.

Tanaka E, Sabry J. 1995. Making the connection: cytoskeletal rearrangements during growth cone guidance. Cell 83:171-176.

Thomas SM, DeMarco M, D'Arcangelo G, Halegoua S, Brugge JS. 1992. Ras is essential for nerve growth factor- and phorpbol ester-induced tyrosine phosphorylation of MAP kinases. Cell 68:1031-1040.

Tomasek JJ, Hay ED. 1984. Analysis of the role of microfilaments and microtubules in acquisition of bipolarity and elongation of fibroblasts in hydrated collagen gels. J Cell Biol 99:536-549.

Wang XM, Peloquin JG, Zhai Y, Bulinski JC, Borisy GG. 1996. Removal of MAP4 from microtubues in vivo produces no observable phenotype at the cellular level. J Cell Biol 132:345357.

Wessels D, Soll D, Knecht S, Loomis W, Delozanne A, Spudich J. 1988. Cell motility and chemotaxis in Dictyostelium amoebae lacking myosin heavy-chain. Dev Biol 128:164-177.

Wood KW, Sarnecki C, Roberts TM, Blenis J. 1992. ras mediates nerve growth factor receptor modulation of three signal-transducing protein kinases: MAP kinase, Raf-1 and RSK. Cell 68:10411050 . 